\title{
Research on Consumption Psychology and Consumption Behaviors in the Mobile Internet Era
}

\author{
Yu Cao \\ Wuhan Donghu University, Wuhan, Hubei, China, 430212 \\ hunter2011@foxmail.com
}

Keywords: Consumption psychology, Consumption behaviors, Mobile internet era.

\begin{abstract}
The integration of the mobile communication technology and the Internet technology leads the human into a new era of mobile internet. With the rapid develop of electronic commerce in the mobile internet era, the consumption psychology and consumption behaviors also transform quickly. This paper firstly gives the concepts of consumption psychology and consumption behaviors, and then analyzes the new features of consumption psychology and consumption behaviors in the mobile internet age in order to provide some references to the related researchers.
\end{abstract}

\section{Concepts of Consumption Psychology and Consumption Behaviors}

Consumption psychology refers to the psychological characteristics and the psychological activities process of the consumption. All consumers' behaviors are dominated by the consumption psychology in the consumption activities. Whether to buy a commodity is consumption psychology. So are the things of what brand to buy, when to buy, where to buy, how to buy and so on. Each step of the process needs the corresponding psychological reactions, analysis, comparison, selection and judgment. Consumption behaviorsare carried out under certain psychological activities.

Consumption behaviorsare decision processes for the consumers to acquire, use, dispose of consumption goods or services, including the decision-making process before and the decision of these actions. Therefore, consumption psychology and behavior is the consumption in a series of psychological activities, to achieve the desired objectives and to make a variety of responses, actions, activities and actions. Consumption behaviors are rich in variety and very complex. The diversity appears as the different consumption demands, preferences and other aspects of the focus of different consumers. The same consumers also have different choice because of different time and different situations. Moreover, consumptions' behavior is influenced by various cultural, economic, individual factors, and these factors have a direct impact on consumption behavior. Some are indirect, some are separate, and others are interactive.

Consumption psychology and consumption behaviors are various. However, they have some common characteristics. Thecommon characteristics are the law of consumption psychology and consumption behaviors which need us to explore.

\section{Consumption Psychology in the Mobile Internet Era}

Consumption psychology in the era of the mobile internet not only has the characteristics of the consumption psychology of the internet era, but also deepened these characteristics.

Personality Psychology. Consumption goods market is prosperousand the majority of products are very rich in the mobile internet age. Consumers can choose and buy goods or services based on the desire of individual psychological desire. Modern consumers are often imaginative, eager to change, like innovation. There is a strong curiosity, a higher demand for personalized consumption. Their choice is not only the practical value of goods, but also to be different, fully reflects the individual's own value, which has become the primary goal of their consumption, personalized has become the mainstream of modern consumption. In the mobile Internet era, this is more vividly reflected. People often buy things from a practical point of view, but from the perspective of the spirit of consumer demand. Online shopping is a positive action from the intention of personal consumption, and its unique shopping environment and the traditional trading process is different 
from the purchase of the consumer's curiosity, detached and personal emotional changes. In this way, consumers can challenge to the businessin order to self-center according to their own ideasin the full performance of the consumer. In view of the consumer's psychological characteristics and changes, more and more shops began to provide personalized custom service. Sports clothing retailer Line Finish and Nikecollaborateto provide personalized services: If a customer chooses a favorite Nike T-shirt, Line Finish will printtheir favorite words- their own name, a famous quote or a number on the Nike T-shirt to meet the consumers' personality psychology.

Speed Psychology. Convenient and high-efficient consumption psychology is common for modern people in mobile internet era due to the limited time. Traditional product selection process is not short, plus the time spent on the road, the consumer a lot of time, energy, and online shopping to make up for this defect. In the mobileinternet era, peoplesave time of shopping in the store through the mobileinternet shopping using cell phones. However, the Internet era, people often need to open the computer, log on to the site.It is able to buy goods on the internet. In the mobile Internet era, people just need to open the smart phone shopping applications, such as Taobao, Tmall, Jingdong Mall and shop very conveniently. Wechat Pay and Alipay and other third payment tools make the rapid payment become a reality. In the logistics field, there are theservices of "next day delivery" and"211 limitedtime delivery". Ordinary expressalso can be reached within a few days.

Trust Psychology. In the internet era, buyers can comment on the product. Their dissatisfaction with the product can also be expressed freely, so we will buy things will go to see other people's comments will be assured, because the business is not entirely credible. For example, in Taobao shopping will usually look at what other people are saying, a high score. We will not assure to buy. But later caused the problem, on the one hand is the vigorous development of the brush list, navy and other business, on the other hand, there are many users may be anything that isn't useful to understand directly to a disorderly group, so the user time to buy things you must keep the information filtering and judge what is true and what information is not reliable, which will consume a lot of time and cost. This contributed to a lot of people in Taobao buy east of the highest selling products directly to buy, and not been too much critical attention, at least I look around a lot of people so. This kind of consumer mentality also caused by selling hot products and in fact some of the day a little bit sad. Everything is still in the development, consumers suddenly found Taobao and many $\mathrm{C} 2 \mathrm{C}$ sellers have a lot of things are not too reliable, regardless of the product quality, delivery speed, and many other small shops are not guaranteed.Taobao launched theTmall to encourage the name of the company to open shop, trust well, big business will fly some of the. So in the case of products meet the requirements, and ultimately contributed to the purchase of the essence is to trust, in the B end shopping is nothing more than a trust company, as we buy appliances on the love to buy, trust has been established, in Taobao buy selling goods is nothing more than a trust to buy more natural will not be wrong. The features of trust in the internet era and the mobile internet era are different.

Sharing Psychology. To be in the home is many young people choice, especially people born in the 1990s. Businesses naturally want to put the marketing battlefield on the network. Compared to the main form of mobile Internet network, the network community marketing seems to be more in-depth impact on consumers such as QQ circle, Wechat friends circle and micoblog friends. In these circles, they are willing to share their own experience, but also willing to accept the experience of others, and then as a basis for their own consumption. Affect the inner circle of a part of people, and then form a circle of word of mouth spread, or enterprise to establish a circle, to create a circle of visibility, are efficient marketing tool. The consumer psychology of the people living in a certain social circle, there is a hope that the social circle of their own should belong to the trend of synchronization. That is not prominent, and do not want to fall behind. This is a very large customer base, which is formed by the consumers with the psychological domination. Research shows that when a certain product consumption rate reached $40 \%$, will produce a consumer boom. Consumers of online goods are many of this mentality of people. The Internet is not necessary to traditional channels, the loss of efficiency of the link are removed.Service providers and consumers manufacturers and consumers more direct docking in a block, consumer 
preferences, hot spots can quickly through the network feedback. This summer, the nickname bottle of Coca-Cola in China sales increased 20\%compared to the same period last year due to the sharing psychology.

\section{Consumption Behaviors in the Mobile Internet Era}

AIDMA consumption behaviors theory is put forward by the American advertising expert E.S. Lewis in 1898. Until today, this theory also fit the undeveloped countries of the information technology. According to this theory, most purchase behavior will be through the following 5 stages: Attention, Interest, attention interest desire to enhance memory Desire Memory and Action contributed to the action of this theory in full compliance with the decision-making behavior of consumers in the Internet era, the birth of one-way flow of information consumption patterns, including A (attention), I (interested in), D (desire), M (remember) for consumers passively accept advertising or selling produced after the reaction, only A (action) is the active behavior of consumers, this theory significance lies in the motivation of combining psychology full decomposition of consumer behavior, make the enterprise have a definite object in view in AIDM four a node to optimize the processing and improve the conversion rate of advertising.
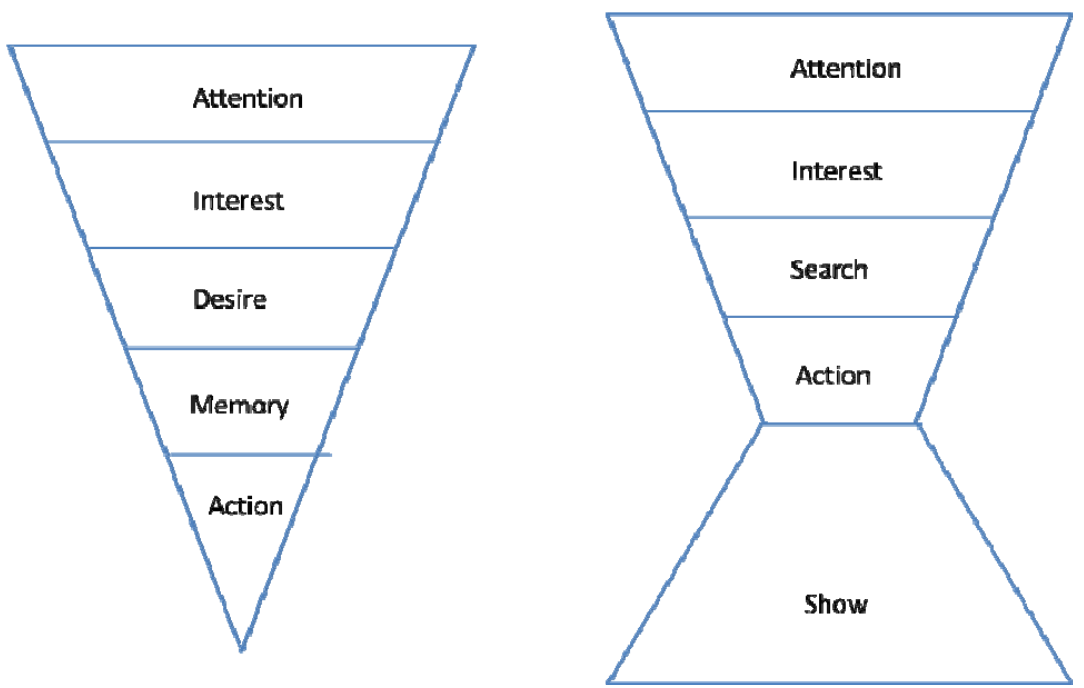

Fig. 1 AIDMA and AISAS models

In the mobile internet era, consumption behaviors evolve into the mobile internet era as SCIAS, as the Figure 1 shows. That is to say, to Search-Compare-Interest-Action-Show. The first step to buy products in mobile internet era is to search the electroniccommerce website, also can be through the search engine, and can also be online through the similar goods or services, if direct in the electricity supplier website search target goods, also will receive the same kind of goods, and will receive the same kind of goods, if consumers still believe that there is demand for a certain product Show (Interest), if the purchase decision; if including hardware, network, station server, payment system, including the entire transaction process without stop, consumers will buy action Show come out after the results are divided into three categories: with the needs of the majority of readers, do not have any real impact, or for the brand to increase their job or goodwill; just as the reader needs, it is possible to directly contribute to the consumer decision-making; if the two is a weak relationship, the reader has such needs compared to the classical theory of information flow in the AIDMA, we can see that the SCIAS model is also the same as the current mobile Internet information dissemination way - without the "end point", the first transaction after the completion of the first transaction will be due to the differences in the strength of the results, which will bring more challenges in various aspects of information processing, because they need to consider more demand scenarios, manufacturing more perfect closed-loop to promote the conversion rate. Search and selection is often carried out, so the category of vocabulary more and more in our life. You took the smart mobile station in a strange place, problems you are experiencing now is a bit hungry, looking for a place to eat, to solve the problem now is very simple, open the map tool positioning 
the location, search the surrounding information, reference other consumer evaluation and per capita consumption. Combined with the cuisine and distance from me, horizontal comparison of each restaurant makes consumption decisions to solve their own problems.

\section{Conclusion}

The arrival of the mobile internet era makes the consumers get information more convenient and quick. Exploring the consumption psychology and behaviors will help the enterprises to improve the profit. This paper studies the subject of the consumption psychology and behaviors of mobile internet environment. In our country, the mobile internet is still in the development stage. The consumption psychology and behaviors research in the mobile internet environment also needs to be deepened.

\section{References}

[1] X.H. Zhu, Research on the Behavioral Intention of Mobile Internet User, Nangjing University of Posts and Telecommunications, 2011.

[2] J. Yang, X.J. Zhang, A Psychological and Behavioral Investigation on Internet Consumption of College Students, J., Journal of Henan Institute of Science and Technology, 6(2013)74-77.

[3] J. He, Study of Female Clothing Consumption Psychology Based on Internet Age, Journal of Zhejiang Textile \& Fashion Vocational College, 2(2015)32-35.

[4] Z.Y. Liu, The Relationship of Consumption Emotion andPurchase Intention in Microblogging Interactivity, University of Jina, 2013. 